\title{
Activity-Centred Analysis and Design (ACAD): Core purposes, distinctive qualities and current developments
}

\author{
Peter Goodyear $^{1}$ (D) . Lucila Carvalho ${ }^{2} \cdot$ Pippa Yeoman $^{3}$
}

Accepted: 26 November 2020 / Published online: 11 January 2021

(c) Association for Educational Communications and Technology 2021

\begin{abstract}
This paper provides a summary account of Activity-Centred Analysis and Design (ACAD). ACAD offers a practical approach to analysing complex learning situations, in a way that can generate knowledge that is reusable in subsequent (re)design work. ACAD has been developed over the last two decades. It has been tested and refined through collaborative analyses of a large number of complex learning situations and through research studies involving experienced and inexperienced design teams. The paper offers a definition and high level description of ACAD and goes on to explain the underlying motivation. The paper also provides an overview of two current areas of development in ACAD: the creation of explicit design rationales and the ACAD toolkit for collaborative design meetings. As well as providing some ideas that can help teachers, design teams and others discuss and agree on their working methods, ACAD has implications for some broader issues in educational technology research and development. It questions some deep assumptions about the framing of research and design thinking, in the hope that fresh ideas may be useful to people involved in leadership and advocacy roles in the field.
\end{abstract}

Keywords Learning activity · Analytical frameworks · Educational design · Design for learning $\cdot$ Teaching-as-design $\cdot$ Design rationale $\cdot$ Design tools

This paper explains Activity-Centred Analysis and Design (ACAD) as an approach to understanding and improving complex learning situations. We outline the essential features of ACAD and identify some ways in which it adds to the sets of ideas and methods already available for research and development in educational technology. The paper falls into four main sections. In the first section we provide a definition and high-level description of ACAD, drawing an important distinction between 'design time' and 'learn-time' views of the world. The second section explains some of the motivation for ACAD, drawing on

Peter Goodyear

peter.goodyear@sydney.edu.au

1 Centre for Research on Learning and Innovation, Sydney School of Education and Social Work, The University of Sydney, Sydney, NSW, Australia

2 Institute of Education, Massey University, Wellington, New Zealand

3 Educational Innovation, Deputy Vice Chancellor (Education) Portfolio, The University of Sydney, Sydney, NSW, Australia 
the pragmatics of messy, real-world analysis and design. We explore some of the relations between ACAD and design inquiry and the 'connecting constructs' that can be used to form the logic of designs for learning. The third main section of the paper summarises two areas of active development: making design rationales explicit and an ACAD toolkit for collaborative design meetings. The final section locates ACAD in relation to some existing areas of research and practice in educational technology.

\section{ACAD: Definition and high level description}

Activity-Centred Analysis and Design (ACAD) is a meta-theoretical framework for understanding and improving local, complex, learning situations. Explaining what this means requires some shared terminology.

We use the term 'activity' to mean 'what students are actually doing' - mentally, physically and emotionally - during a period of time in which they are meant to be learning something (a learning episode or 'at learn-time'). For better or worse, what students actually do may differ considerably from what their teachers think they are doing or what their teachers intend them to do (Goodyear 2000; Ellis and Goodyear 2010; Elen 2020; Koh and Kan 2020).

We use the term 'learning situation' to underscore the point that students' learning activity is always situated (Lave and Wenger 1991; Yeoman and Wilson 2019). As we explain later on, we take this to mean that learning activity is (at a minimum) physically, socially and epistemically situated. The more familiar term 'learning environment' does not reliably evoke all aspects of what makes learning activity situated.

We use the term 'local' because we also see educational work as situated (Pink 2012; Simonsen et al. 2014). It is done by real teachers in concrete situations. ACAD helps a teacher or team of teachers, with or without the help of a specialist educational designer or evaluator, to understand a learning situation in which they have a stake - where they have professional responsibility for students' learning, some power to change aspects of the design of the learning situation, a need to understand how their students' learning activity unfolds, and why it unfolds in the way that it does. Teachers' work is usually cyclical. Although this is not universally the case, it is common to teach a course once a year, to analyse what is working well and why, and decide what needs changing and what can be left as it is. ACAD can help with brand new designs, but it has greater power when embedded in cycles of incremental improvement (Goodyear and Dimitriadis 2013).

We use the term 'complex' to indicate that teachers do not need an analysis and design methodology to diagnose simple problems and prescribe simple remedies (Ellis and Goodyear 2019). ACAD has a dual focus - analysing and understanding what exists and (re) designing for the future. This means ACAD also has a dual ontology, insofar as an actual instance of a learning activity and a design for future instances of similar learning activities are not the same kinds of thing. A map is not the territory. We see ACAD as meta-theoretical in that it does not insist on any one theory of learning. Indeed, it is agnostic about the kinds of theoretical explanations that are used in analysing learning situations and the kinds of design rationales expressed in designing for future learning. However, ACAD does highlight the need for credible explanations of local phenomena and for persuasive arguments in making design decisions.

It is easiest to sketch the essence of ACAD in the familiar circumstances of formal education. Terms like 'student' and 'teacher' are easy to comprehend in that context. However, 
the development of ACAD has occurred in a wide variety of contexts: in schools but also in higher education, vocational education and in non-formal and informal learning. We use the term 'teacher' to include all those people who have a professional responsibility to support other people's learning, wherever they work and whatever their job title. In this paper, when it makes the explanation clearer, we also distinguish people who have a more specialised responsibility to (help) design for other people's learning: educational and/or instructional designers and developers. Where required, we draw out the designerly aspects of teachers' work by talking about teacher-designers or teaching-as-design (Goodyear 2015).

ACAD has also been used in situations where the people involved have not thought of themselves as learning anything: where learning is a barely-noticed by-product of engagement in community action (Carvalho and Goodyear 2014). So, to understand the full span of ACAD, it is helpful to think more generally. People participate in activities and they may learn something as a result. Through their participation, they customise and reconfigure aspects of the (learning) situation - to the point where it may be reasonable to regard them as co-designers. Becoming a more autonomous learner - more self-aware, better at self-managing - also involves learning how to reconfigure situations to make learning more effective, efficient or enjoyable (Markauskaite and Goodyear 2017).

It is also easiest to explain the added value of ACAD in circumstances where (1) students are engaged in 'active learning' or 'learning by doing' and (2) students' activity is unsupervised, or only lightly supervised, by their teachers. The nature of students' activity is crucially important in determining what they succeed in learning. Since, by definition, teachers have little or no opportunity to intervene during lightly supervised learning activities, upfront design ('teaching-as-design') becomes very important. Students engage in a good deal of learning activity without direct supervision, or with only light supervision. We might go further and say that it is actually very rare - across all sectors of education and training - for a teacher to have detailed, accurate knowledge of what a student is thinking, to the point where they can reliably fine-tune individual learning activities on-the-fly (Calderhead 1984; Hativa and Goodyear 2002).

It is partly because of this need to be able to design for situations where close supervision by teachers at learn-time is difficult or impossible, that ACAD is centred on students' activity at learn-time. This activity-centred approach distinguishes ACAD from design approaches that are teacher- or instructor-centred, content-centred or technology-centred.

In the next two sub-sections, we look inside the ACAD framework and explain its main components and their relationships, as seen at 'learn-time' and at 'design time'.

\section{ACAD: The view at learn-time}

Students' actual activity emerges in response to a range of non-deterministic influences. The external influences can be categorised in a number of ways, but with ACAD we use a simple tripartite approach, arguing that students' activity is epistemically, physically and socially situated. In other words, what students do is substantially influenced by (i) the tasks they are set, (ii) the tools and other resources that come to hand, and (iii) what the people around them are doing.

Many explanations of what students do implicitly or explicitly refer to activity as resulting from an interplay of structure and agency. That is, students exercise autonomy but they do so within circumstances that are not (entirely) of their own making (Ashwin 2012). The term 'structure' can conjure up images of landscape and of students moving through the landscape in ways that reflect both their intended destination and the nature of the ground. 
Such imagery also serves to reinforce the idea that activity is situated within various kinds of scapes, settings or containers. We prefer a more fluid interpretation. When we say that activity is physically situated, for example, we mean to include both (a) the influence of qualities of a place and (b) the way that physical things - such as tools and other kinds of artefacts - become woven into and affect activity. In other words, the physical world is not, or is not simply, a box within which activity is contained; it is constituted of things that become meshed together, and unmeshed, in activity (Goodyear et al. 2016). Similarly, when we say that activity is epistemically situated, we mean to include both (a) the role of knowledge-laden task specifications in giving students suggestions about directions in which to travel, and about good things to do on the way, and also (b) a recognition that students, as people, are always already doing a number of things, in which various forms of knowledge and ways of knowing play a part. And when we say that activity is socially situated, we include both (a) social norms and resources and (b) interactions with peers and others in co-operative work.

Figure 1 provides an ACAD view on the architecture of learn-time. Students' activity is central. It is at the heart of the matter. It needs to be understood as real, in that it exists independently of designers' or teachers' beliefs about what is or should be happening and it has direct consequences for what students actually learn (Goodyear 2000). Student activity at learn-time is also emergent, in that it is influenced but not determined by the epistemic, physical and social situation. Rather, the activity emerges from processes of co-configuration, in which students customise what has been designed and set in place for them: selecting from, adding to, re-interpreting and otherwise modifying what has been proposed. This co-configurative work often mixes elements that exist in the student's lives outside formal education ('inherited' elements) with elements designed specifically for them and their current learning activity and situation ('designed elements'). A simple example would be when students combine the use of a website that has been designed specifically for their

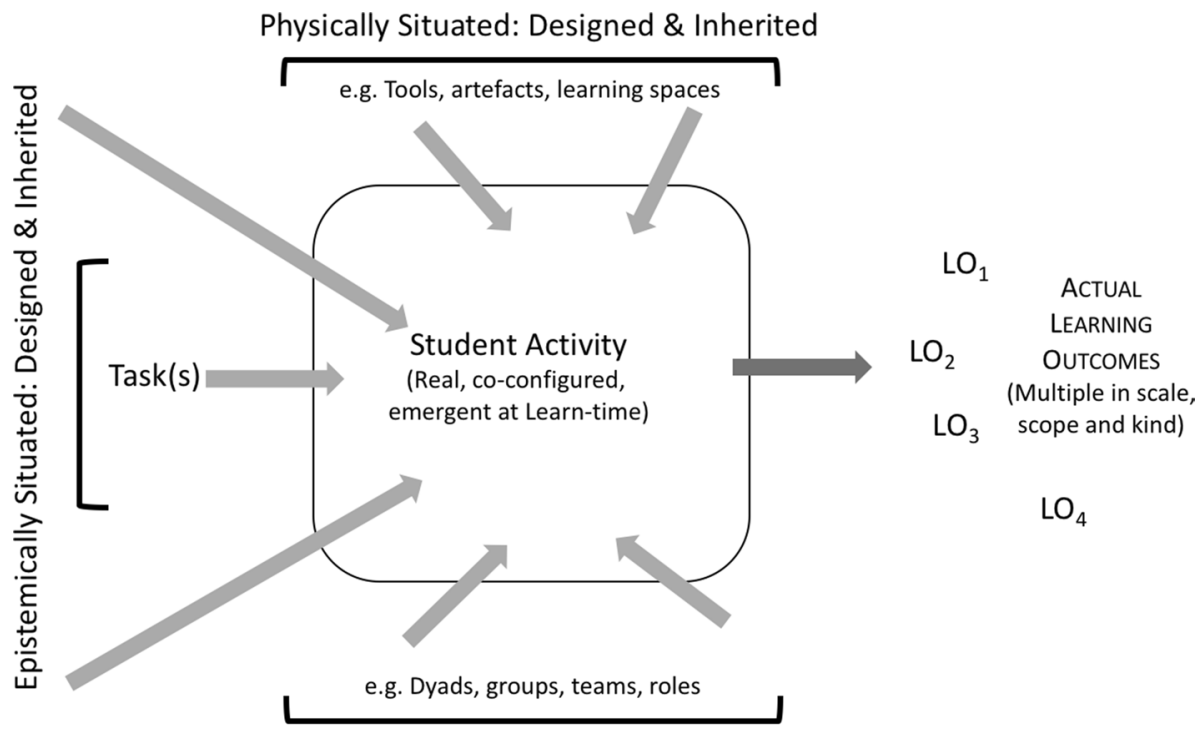

Socially Situated: Designed \& Inherited

Fig. 1 ACAD at learn-time: the architecture of situated learning 
course with their preferred social networking app, to liaise with other students (Goodyear 2000; Sun 2018; Sun and Goodyear 2019).

A further point to note from Fig. 1 is that there are no direct causal links between (a) things that can be designed and (b) actual learning outcomes. Design proceeds indirectly. For example, there is no sense in looking for direct causal links between a new digital tool and learning outcomes, because such connections are always mediated by what students actually do. This is one of the reasons that research studies correlating technologies with outcomes are of limited use in real-world design decision-making (Goodyear and Ellis 2008). Finally, activities normally have multiple outcomes. These may be different from intended outcomes. The existence of a multiplicity of outcomes for any one activity means that research studies which rely on a single outcome measure are rarely of much use in guiding real-world design decisions.

\section{ACAD: The view at design time}

Figure 2 takes us to (re)design time. ACAD's conception of the design problem space reflects the architecture of learn-time, but it is not exactly the same. Figure 2 uses a heuristic distinction between four kinds of designable components: epistemic (task), physical (set), social and intended learning outcomes. In other words, it divides what can be designed into:

- Tasks: suggestions of good things to do, and knowledge on which to draw, in the service of learning.

- The physical resources that may be useful in carrying out the suggested task(s): including material, digital and hybrid tools and other artefacts, learning spaces, etc.

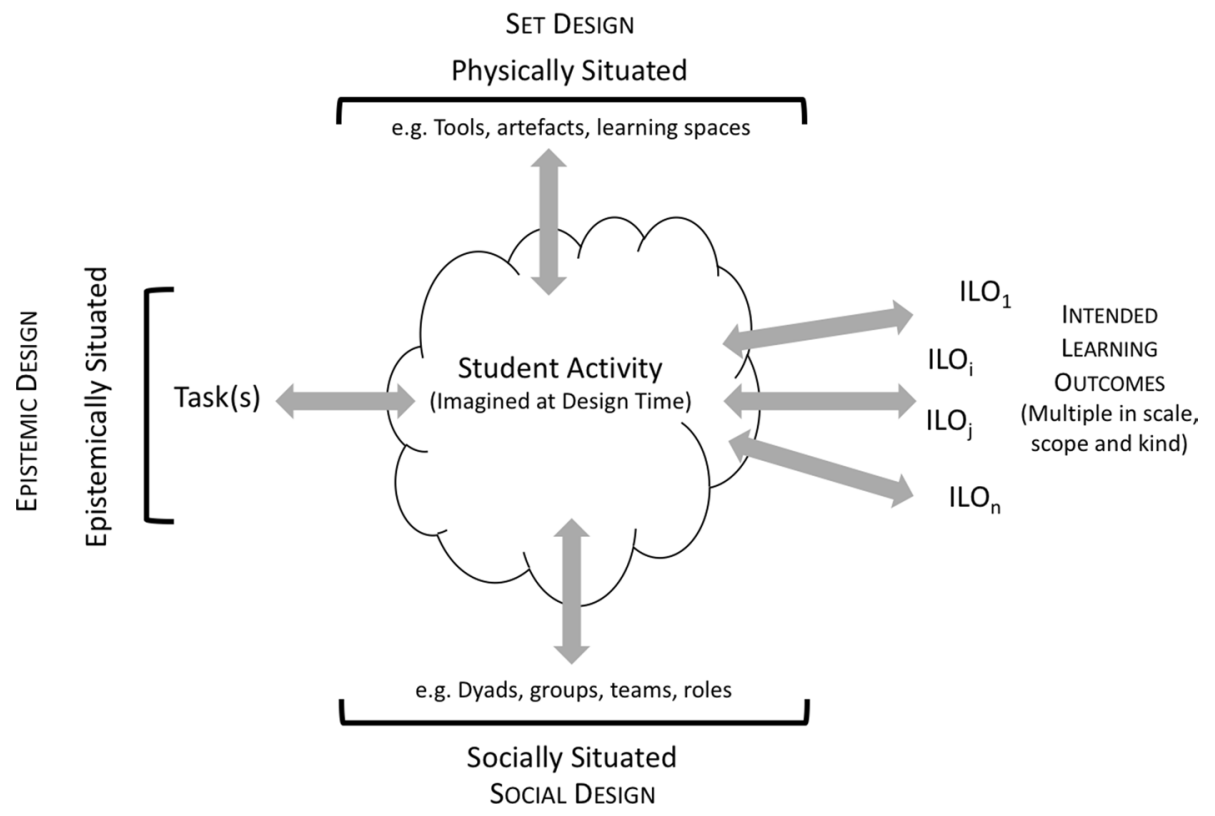

Fig. 2 ACAD at design-time: conceptualising the design problem space 
- Proposals about ways students may work with their peers: groupings, roles, divisions of labour, learning networks and communities etc.

- Intended learning outcomes: including specific, proximal, general and distal outcomes.

The double-headed arrows indicate that design thinking may rove back and forth between provisional design ideas. For example, when a teacher-designer is imagining what students will do in response to a proposed task (epistemic design) and division of labour (social design), they can use this to work out what tools and other physical resources (physical/set design) may be most useful to recommend. In different circumstances, a designer may have to redesign a task and student groupings to fit an activity into a new set of learning spaces, or to accommodate for a shift in the activity from face-to-face to online. In short, at design time, design thinking typically moves backwards and forwards across imagined student activity, aspects of the physical, the epistemic and the social, and intended learning outcomes.

While these four kinds of designable components can be thought of separately, as part of exploring design possibilities, a crucial message from Figs. 1 and 2 is that they become enmeshed together in students' activity at learn-time. This is a useful corrective to habits of design and research thinking that privilege one kind of component over others - such as prioritising technological 'things' over educational problems (Reeves and Lin 2020). For example, much of the writing about innovative learning spaces privileges the physical, giving it undue autonomy or causal power, and fails to appreciate that rearrangement of physical space, on its own, will not produce beneficial educational change (Carvalho et al. 2017; Ellis and Goodyear 2016; Goodyear et al. 2018; Yeoman and Wilson 2019). The same can be said of digital tools (like iPads), pedagogical techniques (like problem-based learning) and social rearrangements (like groupwork). None of these functions independently.

\section{The motivation for ACAD in the pragmatics of analysis and design}

Research on (human) learning aims to provide accounts of learning that are true across a wide range of situations: the goal is to make and test conjectures and develop theory, without close attention to the needs of those who will use the knowledge about learning thereby produced. We know that many educational practitioners see little value in consulting the research literature (Broekkamp and Van Hout-Wolters 2007; Vanderlinde and van Braak 2010; Goodyear 2011). We also know that teacher-designers struggle to make use of general principles about 'good learning' when they have to make concrete decisions during educational design (Hoogveld et al. 2002; Kali et al. 2011; Kali et al. 2015; Goodyear et al. 2018).

Understanding the development and logic of ACAD requires a switch of view: from the science of learning to the pragmatics of educational design. 'Pragmatics' is concerned with action - with how people make sense of things, and get things done, in real world contexts. ACAD aligns with the need for actionable knowledge.

There is considerable variation in the practices of educational design, so some simplification is necessary to make further progress with our explanation. In what follows, we focus on the redesign of ongoing courses, as distinct from the design of new courses (Goodyear and Dimitriadis 2013). We will also focus on situations in which redesign is done by two or more people, such as when a teacher or a course team works with one or 
more educational designer/developers, in a process which involves several meetings. We refer to this temporary grouping of people as a course redesign team.

The work process we associate with periodic redesign of this kind has the following characteristics:

- It sits within a cycle - often an annual cycle - of design, enactment, analysis and redesign.

- This cycle has its own temporal discipline. For example, there may be only a limited period each year in which the course design can be modified; analysis therefore needs to be timely and actionable.

- Tight periods for redesign, and limited person-power, mean prioritising what should be changed: e.g. on the basis of what students said and did, or in light of some other notions of quality enhancement, or because of enforced changes, such as spaces or tools no longer being available, worsening staff-student ratios, new demands by certifying bodies, etc.

In short, analysis and design should not be thought of in idealised terms. A course that operates in the real world is not an idealised object open to infinite manipulation by omniscient instructional designers. It is subject to real-world processes of change, involving course redesign teams who have to make decisions efficiently, with uncertain knowledge, incomplete data and finite resources, at fixed times, in the midst of competing priorities.

In such circumstances, the creation of useful knowledge has to concentrate on revealing - to a mutually acceptable level of detail and reliability - how the current set of educational arrangements actually works. Expressed in other terms: how does this learning environment (or system, or network) actually function? And what is likely to happen if one tries to change part of it? With most real-world learning systems, answers to these questions are rarely self-evident and they are not necessarily easy to arrive at through talk alone. More likely, the course redesign team - the people who have a stake in improving things - need to create, test, discuss, improve and agree to use some shared representations, as aids to coordinated sense-making and action (Ison and Blackmore 2014).

\section{ACAD and design inquiry}

A course redesign team, in such circumstances, may engage in design inquiry in order to come to a shared understanding of how the course functions. It needs to map or remap the architecture of each of the major learning activities constituting the course and explain how relations between the main physical, social and epistemic components generate valued, or problematic, local functions. Part of the challenge here, expressed in the language of realist evaluation, is to explain how specific local mechanisms produce outcomes (Wong et al. 2012).

This focus on the local, situated, specific and contextualised (in ACAD) places design inquiry as a form of idiographic research. Educational technology research 'does not have a distinguished record in dealing with local educational problems' (Reeves and Lin 2020). Idiographic research aims to identify particular connections characterising specific cases. It contrasts with the much more familiar nomothetic research, which aims to establish generalisations across cases.

Design theorists Nelson and Stolterman (2014) point out that design inquiry actually aims to create three kinds of useful knowledge - knowledge of what is true, what is real 
and what is ideal. In brief, knowledge of what is true includes universal statements and generalisations, such as those which aim to explain fundamentals of how human beings learn, the nature of cognition, limits to working memory, etc. Such knowledge is also very useful in explaining how to connect the physical elements in a learning environment: knowledge of electronics and mechanics, for example. In contrast, knowledge of what is real concerns specific, existing entities, objects, events, etc. To understand this class, this course, these students, this learning activity involves inquiring into something that is real. Finally, inquiry into the ideal concerns the clarification of values and purposes. Design inquiry often has to pursue questions about what is actually needed, what deeper human purposes are served, what the actual ILOs should be, and so on.

On this view, a course redesign team, working with the ACAD framework, moves back and forth between design inquiry and design action - exploring and coming to a better shared understanding of the real and the ideal, illuminated by knowledge of what is (more generally) true. The explanations and representations they create have potential value for future redesign work and they can also help the team to articulate design rationales, to share with students and other practitioners (Krippendorff 2006).

\section{Design thinking and 'connecting constructs'}

Periodic course redesign involves thinking carefully about the relations between quite diverse kinds of elements. We use the term 'connecting constructs' for ideas that capture these relations. Connecting constructs provide the logic for a design. For example, within the 'physical' or 'set' design area are to be found many discrete but interconnected, or interconnectable, things - material, digital and hybrid, small and large, local and distant, tools, artefacts and infrastructures - which need to be brought into productive relations in order to function. Consider, for example, the components that constitute a Virtual Learning Environment or Learning Management System, together with a set of 'Office' tools (a word-processor, spreadsheet tool, etc) and a suite of communications and social media (Facebook, Twitter, email, etc.) A course team typically populates the VLE with specific course materials and makes recommendations to students about the 'Office' and communication tools that should be used. Within this broad and heterogeneous domain of 'physical' elements, the prevailing logics derive from positivism: explanations or models of how things fit together, take inputs and create outputs, enclose and support one another, and so on, depend upon physical laws, topologies and spatial relations. Within the 'social' design area, other logics apply, not least because the people caught up in designs for learning have their own intentions and can interpret what they are being asked to do. In this social domain, design decisions cannot depend upon the same kind of positivist logic that is relied upon in the physical domain. Interpretivist accounts are also needed - to foresee how students may interpret and complete what has been designed for them (Krippendorff 2006; Sun and Goodyear 2019).

Design decisions are not limited to the three distinct domains of the physical, social and epistemic, of course. Much of the design thinking and decision-making that has to be done necessarily focusses on the interface between activity (what students will actually do) and design elements in the physical, social and epistemic domains. As we have said, activity - being emergent and real - is not designable. However, design decisions that affect what is made available and/or recommended in the physical, social and epistemic domains depend on assumptions about relations between these designable elements and what it is imagined that students will then do. For example, relations between student activity and the physical 
can be thought about using connecting constructs such as the ideas of affordances and constraints. A physical environment affords some possibilities for action, but not others. Thus, understanding technological affordances is a key part of the knowledge base on which course redesign teams can draw in making reasoned design decisions. Similarly, there is a well-established body of research on how students interpret the requirements of tasks set for them: how they transform the task set into their actual activity (Ellis and Goodyear 2010). Table 1 provides a summary of the main sets of design decisions required and the areas of knowledge from which connecting constructs can be drawn.

A strong implication to be drawn from Table 1, in light of our earlier arguments, is that research and development in educational technology aimed at connecting or aligning educational outcomes with technological 'things' (Reeves and Lin 2020) needs to (a) also deal with the mediating influence of student activity and (b) draw upon the science of ergonomics (human factors) as well as the learning sciences.

In the next two sections, we share some recent developments in the use of ACAD. Firstly, we discuss some work on making design rationales explicit, to share with students and/or to facilitate rapid adaptation of designs to meet changing circumstances. Then we describe an ACAD-based toolkit for use in collaborative design meetings.

\section{Making design rationales explicit}

Figure 3 is an abstract design representation. Compared with Figs. 1 and 2, it omits 'Activity', because activity, by definition, cannot be designed. We use the term 'simplest possible design representation' (SPDR) to indicate that ACAD conceives of no simpler representation. Design for learning must always take into account the three areas of task, physical and social design. Intended learning outcomes give purpose to the design.

The SPDR also shows how these four are related. The intended outcomes provide a rationale for the task design $\left(\mathrm{R}_{\mathrm{t}-\mathrm{o}}\right)$. This does not necessarily mean that the task design is deduced from the intended learning outcomes. In actuality, teacher-designers work back and forth between various kinds of design ideas, constraints, the balance and choices between valued outcomes, and so on. Similarly, the SPDR in Fig. 3 includes a rationale connecting task design to physical design $\left(\mathrm{R}_{\mathrm{t}-\mathrm{p}}\right)$ and task design to social design $\left(\mathrm{R}_{\mathrm{t}-\mathrm{s}}\right)$. Such

Table 1 Areas of knowledge (of what is true and/or ideal) that can inform design decisions

\begin{tabular}{|c|c|}
\hline Design decisions referring to ... & Appropriate knowledge base(s) on which to draw \\
\hline Physical & Physical laws, topology, spatial relations \\
\hline Social & $\begin{array}{l}\text { Social psychology; social anthropology; cultural studies; } \\
\text { sociology }\end{array}$ \\
\hline Epistemic & $\begin{array}{l}\text { Epistemology; philosophy of science; curriculum studies; } \\
\text { sociology of knowledge }\end{array}$ \\
\hline Outcomes & $\begin{array}{l}\text { Epistemology; workplace research; skills analysis; analysis of } \\
\text { capabilities and competences }\end{array}$ \\
\hline Physical:activity relations/interface & Ergonomics (human factors) \\
\hline Social:activity relations/interface & Group work; collaborative learning; communities of practice \\
\hline Epistemic:activity relations/interface & Students approaches to learning (SAL) \\
\hline Outcomes:activity:task relations/interfaces & Pedagogy; learning theory \\
\hline
\end{tabular}


Fig. 3 The simplest possible design representation (SPDR)

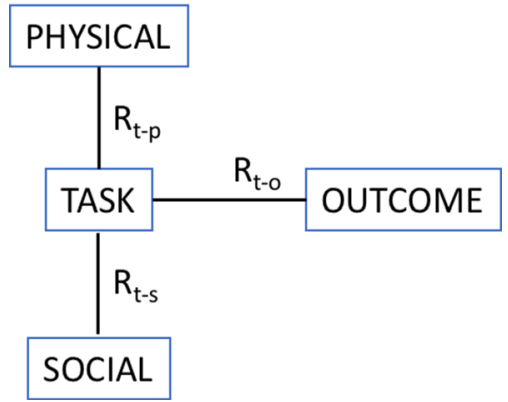

design rationales connect, and provide some explanation and/or justification for, parts of the completed design. In actuality, many elements comprising the physical design may be outside the control of the designer: the task design may, in some ways, reflect unchangeable affordances and constraints in the learning spaces or digital tools available. Conversely, as some aspects of the task design begin to crystallise, they may place requirements on the spaces that will need to be found, and furnished, or the tools and other resources that will need to be recommended, or set in place. Thus, these three design rationales $\left(R_{t-o} R_{t-p}\right.$ and $\mathrm{R}_{\mathrm{t}-\mathrm{s}}$ ) express the logic of the connections, as part of the explanation of the design itself.

The value of including design rationales derives from at least two sources. Firstly, providing an explicit design rationale helps with adapting, communicating, sharing and reusing designs (Goodyear and Retalis 2010; Laurillard 2012; Bearman et al. 2020). Secondly, providing students with explicit design rationales - in principle - strengthens their ability to complete (co-configure) the design before and during 'learn-time' and their ability to configure their own learning tasks, environments and relationships into the future. Research by our doctoral students (e.g. Dave 2017; Sun and Goodyear 2019; Spence 2020) and others (e.g. Beckman et al. 2019; Arnesen et al. 2020) suggests that, at least in higher education settings, teachers only rarely share explicit design rationales with their students, and that students, unsurprisingly, deviate widely from their teachers' intentions (Ellis and Goodyear 2010). In situations where supervision of students' learning activities is 'lighttouch', it may be some time before unproductive drifting away from the task-as-designed is noticed.

ACAD SPDRs, including their design rationales, can also assist in thinking about two kinds of design variations relevant to challenges that are particularly salient right now.

This paper is being written during the Covid-19 pandemic: a time in which educational institutions and their teachers, administrators and students have found themselves (a) adjusting rapidly between different educational modalities and (b) having to deal with uncertainties about which modalities will be available in the short, medium and longer term. The vertical axis of Fig. 4 reflects this, in a simplified way. The 'online pivot' of March 2020 saw many schools and universities shift from their normal arrangements for teaching and learning to what has been called 'Emergency Remote Teaching' (ERT) (Hodges et al. 2020). At the time of writing (July-August 2020), many institutions are planning for a return to some version of socially/physically-distanced 'on campus' educational arrangements, but they are also having to make back-up plans in case educational provision has to revert to ERT or to some hybrid form that mixes face-to-face, online, synchronous and asynchronous activity. So the vertical axis of Fig. 4 shows how variants of a design may be prepared for each of these sets of circumstances, and more. The key point is that a single design (task:physical:social) can be produced, and then variants of it can be 


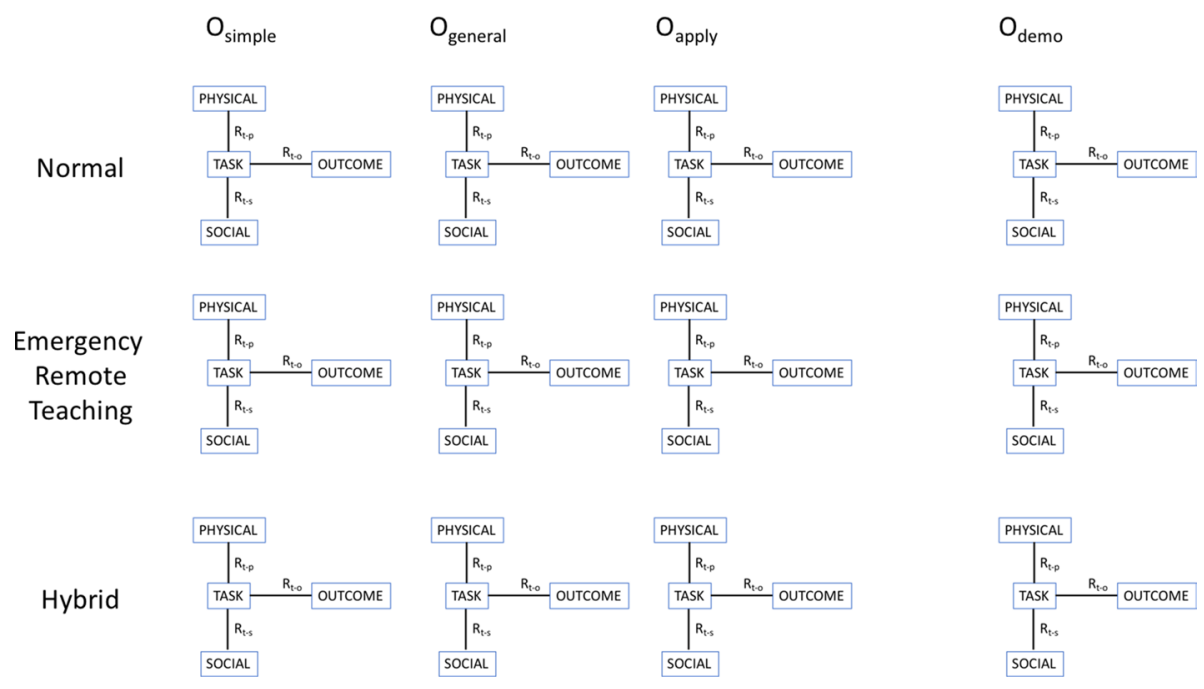

Fig. 4 ACAD SPDRs capturing variations on a design

generated, depending on foreseeable changes in the operating environment. The key corollary is that if the design rationales are also made explicit and shared, students (and others) are better placed to fine-tune further adaptations - to co-configure - if the circumstances in which they find themselves change, or do not exactly match those envisaged by the teacherdesigners. So, for example, a student may be better placed to say to themselves "Tool X was recommended on the assumption that I would need it to do Y, in space Z; I still need to do Y, but in space A, so I'll use Tool B instead".

In a similar vein, the horizontal axis of Fig. 4 reflects variations on a design, mainly reflecting some details of intended outcomes. For example, many instances of 'learning by doing' - in (cognitive) apprenticeship mode - involve students in working on a simplified or partial task, drawn from real-world practice in a professional or academic domain. The rationale for a basic version of such a task may be as simple as saying that experiencing a fragment of professional practice provides a taste of, or foundation for, engaging in that practice later on $\left(\mathrm{O}_{\text {simple }}\right.$, in Fig. 4). However, a richer learning task can be designed that builds upon such simplified experience, by adding a sub-task to encourage generalisation $\left(\mathrm{O}_{\text {general }}\right)$ and/or application $\left(\mathrm{O}_{\text {apply }}\right)$ of insights or skills deriving from $\mathrm{O}_{\text {simple }}$. Engle's work on 'expansive framing' provides an underpinning for this approach. See Engle et al. 2012.)

Among the emergency educational arrangements that have had to be made during the Covid-19 pandemic, some have related to socially-just assessment. Given unequal access to digital platforms (such as online assessment and proctoring systems) and/or to material spaces (such as exam halls), how can assessment practices be quickly and fairly adapted to allow students to demonstrate that they have met course requirements? Design $\mathrm{O}_{\text {demo }}$ captures this. Rather than being a design aimed at helping a student reach outcome $\mathrm{O}$, it provides them with an opportunity to demonstrate that they have already reached outcome $\mathrm{O}$. In other words, it is a summative assessment design rather than a design for learning. So, tracking $\mathrm{O}_{\text {demo }}$ down through variants for 'normal', 'ERT' and 'hybrid' situations shows how preparations can be made - and rationales communicated to students - for different eventualities. To be clear, the point is not to cover all eventualities, but to cover what is 
easily foreseeable and to share the design ideas that help students, and those around them, customise and complete designs more effectively and efficiently at learn-time.

\section{Tools for collaborative design meetings: the ACAD toolkit}

Drawing on tools used in design anthropology (Gunn et al. 2013) and on research in educational design (Carvalho 2010; Chatteur 2011; Yeoman 2015), the ACAD toolkit (Yeoman and Carvalho 2019) was created to facilitate theoretically-informed educational design practices. The ACAD toolkit supports course design teams by scaffolding the processes of knowledge sharing and knowledge integration (McDonnell 2009) using conversational prompts that promote the negotiation of shared meaning, with respect to valued forms of learning activity. This support is provided in the form of visual scaffolds and manipulable representations of the ACAD framework and includes a set of colour-coded ACAD cards, the ACAD wireframe, task scaffolds, learning scenarios, and images.

\section{The ACAD cards}

One of the challenges of putting the ACAD framework to work has been helping inexperienced teacher-designers identify and remember the main dimensions of design and focus their work on designable elements of each. Unscaffolded, they tend to spend more time trying to identify dimensions and elements rather than engaging in productive educational design. In response, the ACAD cards (Fig. 5) were developed to seed conversations with a range of examples. Each card represents a dimension of design (using three different colours) and carries a headline term (a designable element of that dimension) for consideration. A fourth colour is used to stimulate discussions about philosophy and high level pedagogy (Goodyear 1999) or valued task types (Law et al. 2017). A core deck consists of around 100 cards. This includes 12 blue cards representing high level philosophy/pedagogy (e.g. socio-constructivism; learning as participation and negotiation: Rogoff 2014) or valued task types (e.g. exploratory learning, students explore issues through conversation), and roughly equal numbers of green set-design cards (e.g. collaborative studio), orange social-design cards (e.g. assigned roles), and yellow epistemic-design cards (e.g. collaborative problem solving). The final selection of terms is refined to suit the specific context and

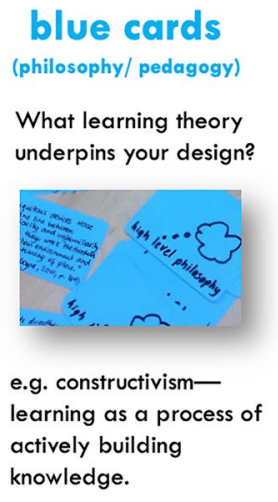

Fig. 5 The ACAD cards
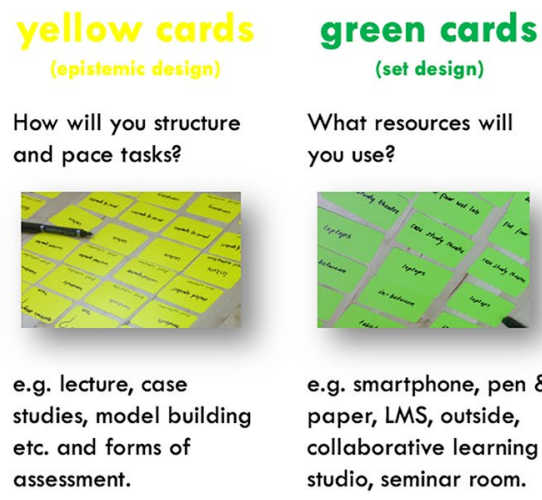

you use?

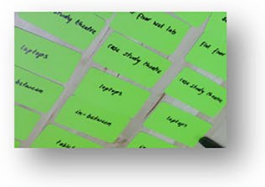

e.g. smartphone, pen \& paper, LMS, outside, collaborative learning studio, seminar room.

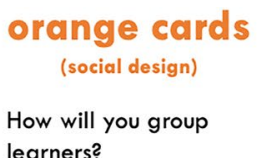

learners?

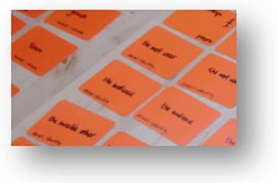

e.g. groups, pairs, scripted roles, notetaker, mentor. 
card decks are assembled from a growing pool of terms. Using more than 100 cards in any one session can be counter-productive. Providing a core deck and options to alter existing cards, or create new cards, offers sufficient structure and opportunities for co-creation.

Teams are encouraged to start with the blue cards, with the aim of establishing a shared understanding of valued learning activity and a common vocabulary - about learning - to discuss a range of potential design solutions. The materiality of the cards is often sufficient to initiate sorting, selecting, and ranking exercises in groups. Words spoken can be fleeting and easily dismissed, but a card with a valued headline term, repeatedly placed in a shared workspace, supports the negotiation of consensus with respect to individual elements of a specific design, the alignment of these elements with valued forms of learning activity, and the coherence of a candidate design. Whilst the cards prompt initial discussion, aligning these designs with values about learning and teaching, and converging on a final design is well served by additional visual scaffolds.

\section{The ACAD wireframe as a visual scaffold}

The primary visual scaffold used by most teams is the ACAD wireframe (Fig. 6). Initially designed to support the analysis of whole-part relationships in fine-grained analysis of learning activity (Yeoman 2015), the ACAD wireframe is a single representation combining the ACAD framework, and earlier work on pedagogical frameworks (Goodyear 1999) and pattern languages (Alexander et al. 1977; Goodyear and Retalis 2010). It acts as a translation device (Bernstein 2000) helping those who use it to navigate between theoretical concepts (high level philosophy) and the enactment of a design (set, epistemic, social) across scale levels (macro, meso, micro). When used to support the work of design teams, it encourages careful consideration of the scale-level at which the team is working (macro, meso, micro) and the characteristics of the scale levels that are beyond their control. This is often a significant moment for teacher-designers, because whilst they are aware that many things are beyond their influence, this exercise highlights the many small but significant aspects that are within their sphere of influence. It helps them find the boundaries of the spaces within which they can act. In addition, when reviewing a potential design, it

\begin{tabular}{|c|c|c|c|}
\hline $\begin{array}{r}\text { Philosophy or } \\
\text { high-level pedagogy }\end{array}$ & $\begin{array}{l}\text { SET DESIGN } \\
\text { Learning is... }\end{array}$ & $\begin{array}{c}\text { EPISTEMIC DESIGN } \\
\text { Learning is... }\end{array}$ & $\begin{array}{c}\text { SOCIAL DESIGN } \\
\text { Learning is... }\end{array}$ \\
\hline $\begin{array}{r}\text { MACRO } \\
\text { The global } \\
\text { Level I patterns }\end{array}$ & $\begin{array}{l}\text { Buildings \& technology } \\
\text { e.g. digital \& physical } \\
\text { infrastructure }\end{array}$ & $\begin{array}{l}\text { Stakeholder values } \\
\text { e.g. forms of knowledge } \\
\text { production \& sharing }\end{array}$ & $\begin{array}{c}\text { Organisational } \\
\text { structures e.g. } \\
\text { hierarchal or networked }\end{array}$ \\
\hline $\begin{array}{r}\text { MESO } \\
\text { The local } \\
\text { Level II patterns }\end{array}$ & $\begin{array}{l}\text { Allocation or use of } \\
\text { space \& technology } \\
\text { e.g. availability \& access }\end{array}$ & $\begin{array}{l}\text { Curriculum } \\
\text { e.g. unit of study, } \\
\text { program or degree }\end{array}$ & $\begin{array}{l}\text { Community } \\
\text { e.g. school, faculty, } \\
\text { cohort or club }\end{array}$ \\
\hline $\begin{array}{r}\text { MICRO } \\
\text { The detail } \\
\text { Level III patterns }\end{array}$ & $\begin{array}{l}\text { Artifacts, tools \& } \\
\text { resources e.g. clock, } \\
\text { BYOD \& furnishings }\end{array}$ & $\begin{array}{l}\text { Selection, sequence } \& \\
\text { pace e.g. content \& } \\
\text { timing of tasks }\end{array}$ & $\begin{array}{l}\text { Roles \& divisions of } \\
\text { labour e.g. facilitator, } \\
\text { groups \& scripts }\end{array}$ \\
\hline
\end{tabular}

Fig. 6 The ACAD wireframe 
encourages discussion about horizontal, vertical, and diagonal alignment: something that is difficult to do well in design groups without access to co-configured visual representations.

\section{Other visual scaffolds}

Other visual scaffolds in the toolkit include an illustration of the ACAD framework (Fig. 7) and a two-by-two grid mapping student autonomy against task complexity (Fig. 8).

The base illustration in Fig. 7 is a version of that shown in Figs. 1 and 2 of this paper. It is used in combination with the ACAD cards and short, scripted, scenarios based on research in formal and informal settings (Carvalho 2010; Carvalho and Garduño Freeman 2018; Yeoman 2015). This combination is helpful for teachers who are unfamiliar with either educational design or the ACAD framework. It involves mapping the scripted scenario using the cards and the illustration. Adding the wireframe then focuses attention on establishing the degree of alignment across dimensions and scale levels, without having to (re)create a learning design.

The student autonomy vs task complexity grid (Fig. 8) is useful for teams involved in curriculum or learning space redesign. It invites candid conversations about educational aspirations and practical enactment in the classroom. For example, if we are redesigning space to support team-based learning, are we prepared to redesign our curriculum to support increased student autonomy? It has also proven to be an effective scaffold for evaluating images of a range of learning spaces.

Originally developed to support the work of heterogenous educational design teams, the ACAD toolkit continues to evolve in response to new opportunities and shifting contexts of use. It has recently been translated into Spanish (Yeoman et al. 2020), and is currently being adapted for use online to support redesign in response to the Covid-19 pandemic.

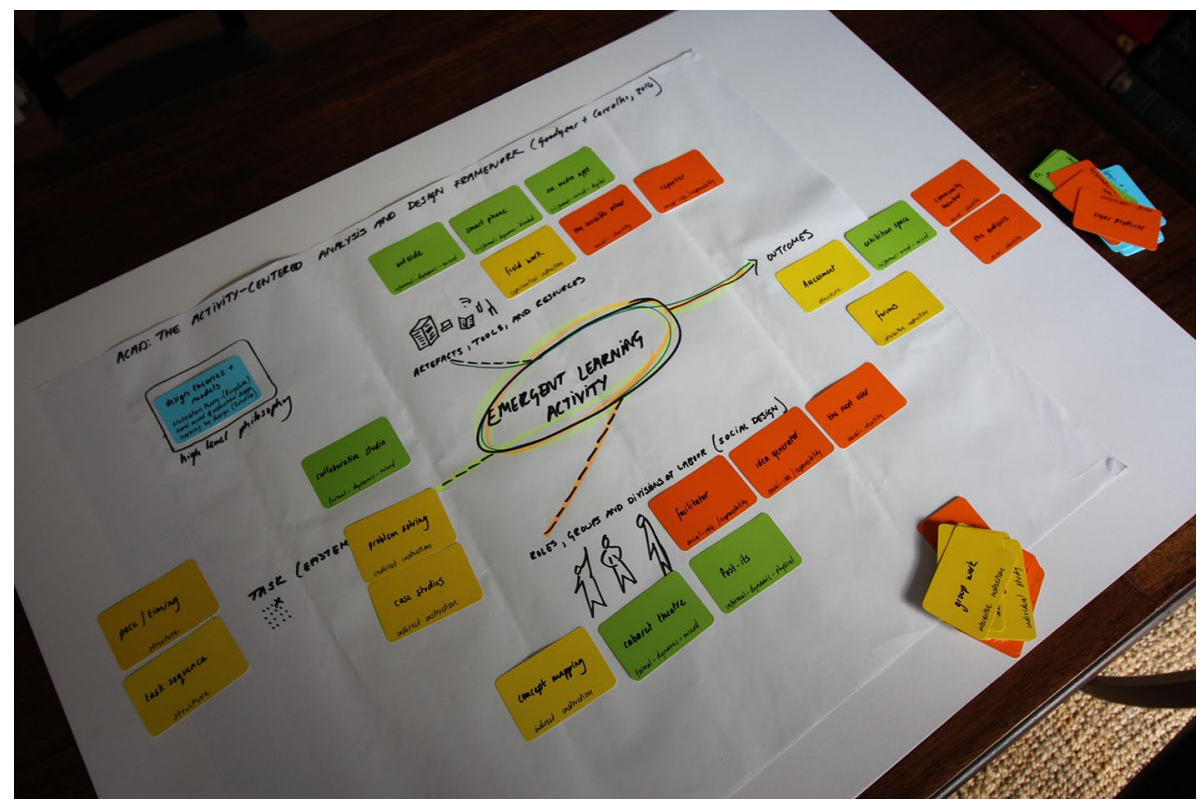

Fig. 7 ACAD illustration in use 


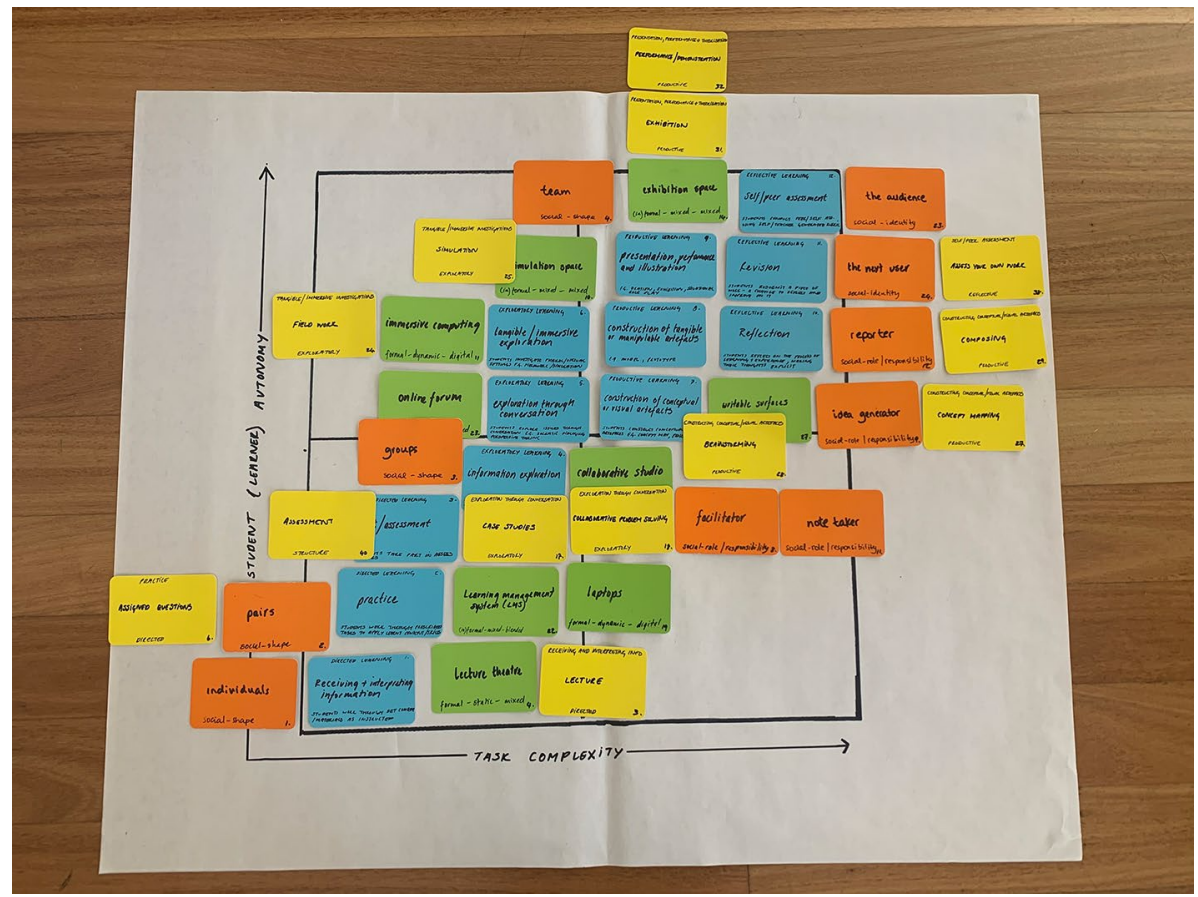

Fig. 8 Autonomy vs complexity grid

\section{Locating ACAD in the broader landscape}

In this last section of the paper, we help position ACAD in the broader landscape of approaches to educational technology research and practice. Given the limits on space, we restrict this comparison to: (a) classic approaches to Instructional Design, such as ADDIE, and (b) Educational Design Research/Design-Based Research. ACAD can fill some gaps and offer fresh ways of thinking about recurring problems in the field. While the ACAD approach can be seen as valuing local, idiosyncratic knowledge over more general or universal knowledge, this would be a misreading. Capable teacher-designers need to be able to draw together the right sets of tools, methods, ideas, data (design knowledge) for each circumstance, and they also need meta-level, strategic, knowledge that can guide them in deciding what kinds of knowledge, and ways of knowing, are most likely to help with the specific design problem at hand. Educational design often involves a high level of epistemic fluency - including an ability to find and use the most appropriate kind of knowledge for each part of the design task at hand (Goodyear 2015). Design typically involves a skilful appropriation and blending of different kinds of knowledge, drawn from a variety of sources.

There are some resemblances between ACAD and classic approaches to Instructional (Systems) Design, such as ADDIE - the Analysis-Design-Development-ImplementationEvaluation model - and 'Backward Design' (Reiser and Dempsey 2017; Wiggins and McTighe 2005; Parchoma et al. 2019). Like ACAD, ADDIE and its relations provide a cyclical framework which involves both analysis and design work. However, there are a 
number of very significant differences. Firstly, ADDIE and Backward Design are essentially process models, aimed at providing guidance to help people step through a complete process (e.g. from analysis to evaluation). ACAD scaffolds analysis and design work by drawing attention to selected sets of phenomena, and their relationships, without specifying a sequence or process to follow. Secondly, ADDIE and BD provide guidance about development and implementation, whereas ACAD is largely silent about these matters - not because they are unimportant, but because (on the ACAD view that learning activities are complex and co-configured) development and implementation are not under the close control of a design/teaching team. Thirdly, analysis in Instructional Design normally refers to analysis of intended learning outcomes and capabilities. Analysis in ACAD is of the whole learning situation. In fact, ADDIE's evaluation phase is closer in focus to ACAD's analysis, though usually narrower in scope. Evaluation, in the ADDIE model, sometimes means checking whether an intervention worked, whereas analysis in ACAD always also involves answering questions about how an intervention worked. Because analysis in ACAD is centrally concerned with understanding causal mechanisms, it is similar to realist evaluation (Pawson and Tilley 1997; Wong et al. 2012).

ACAD also resembles Educational Design Research (EDR) and Design-Based Research (DBR), insofar as EDR and DBR acknowledge the importance of contextual factors in shaping the success or failure of a designed intervention and so insist on carrying out research and iterative cycles of enhancement in real-world contexts (McKenney and Reeves 2019; Reimann 2011; Barab 2014; Zheng 2015). Two major differences separate EDR and DBR from ACAD. First, EDR and DBR are heavily invested in theory-building. Although EDR and DBR are always committed to having beneficial local impacts, they are also driven by an ambition to strengthen theory (Barab 2014; Sandoval 2014; Reeves and Lin 2020). EDR and DBR projects are almost always initiated and led by academic researchers who need to publish theoretically interesting results in journals: to contribute 'knowledge of what is true' (Nelson and Stolterman 2014). Understandably, this affects how they conceive and bound their primary units of analysis (Dohn 2020) and how they prioritise specific lines of investigation. In contrast, ACAD's commitment to understanding specific local systems and how they function ('knowledge of what is real') means that the unit of analysis is conceived and bounded in local terms, in ways that have meaning for the participants. The second major difference is that, paradoxically, the DBR literature evinces very little intellectual interest in the practices of design, whereas ACAD has been informed by, and has contributed to, the mainstream literature of design studies (Carvalho and Goodyear 2018; Yeoman and Carvalho 2019).

In sum, ACAD brings to the table:

- An insistence on recognising students' agency, such that designed tasks must be distinguished, conceptually, from students' activity at learn-time. Only their activity has a direct connection to learning outcomes.

- Ways of reasoning about all the designable and inherited elements that situate students' learning activity.

- An over-riding commitment to methods of understanding and improving local educational situations - helping equip the teachers, designers and students who inhabit those situations to make sense of what is intended and what transpires. 
technology and design: architectures for productive networked learning). Discussions with colleagues, over many years, have played a very substantial role in shaping our ideas, though they will not necessarily agree with everything we have written here (for which we take full responsibility). We would particularly like to thank Kate Thompson, Ana Pinto, Lina Markauskaite, Roberto Martinez-Maldonado, Cristina GarduñoFreeman, Susan Sun, David Ashe, Dewa Wardak, Martin Parisio, Andy Dong, Chris Jones and Christine Smith.

\section{Compliance with ethical standards}

Conflict of interest The authors declare that they have no conflicts of interest.

Ethical approval The research on which this paper draws was part-funded by the Australian Research Council. The Human Research Ethics Committee of The University of Sydney provided approval for the research work (HREC Project Ref 14814). This paper does not report research involving human subjects.

\section{References}

Alexander, C., Ishikawa, S., \& Silverstein, M. (1977). A pattern language. Oxford, UK: Oxford University Press.

Arnesen, T., Arnesen, T.-E., \& Elstad, E. (2020). Exploring students' explanations for off-task practices in an innovative learning environment (ILE) using a typology of agency as theoretical framework. Pedagogy, Culture \& Society, 1-18. https://doi.org/10.1080/14681366.2020.1777461.

Ashwin, P. (2012). Analysing teaching-learning interactions in higher education: Accounting for structure and agency. London: Continuum.

Barab, S. (2014). Design-based research: A methodological toolkit for engineering change. In K. Sawyer (Ed.), The Cambridge handbook of the learning sciences (2nd ed., pp. 151-170). Cambridge: Cambridge University Press.

Bearman, M., Lambert, S., \& O'Donnell, M. (2020). How a centralised approach to learning design influences students: A mixed methods study. Higher Education Research \& Development, 1-14. https://doi. org/10.1080/07294360.2020.1792849.

Beckman, K., Apps, T., Bennett, S., Dalgarno, B., Kennedy, G., \& Lockyer, L. (2019). Self-regulation in open-ended online assignment tasks: The importance of initial task interpretation and goal setting. Studies in Higher Education, 1-15. https://doi.org/10.1080/03075079.2019.1654450.

Bernstein, B. B. (2000). Pedagogy, symbolic control, and identity. Lanham: Rowman \& Littlefield.

Broekkamp, H., \& Van Hout-Wolters, B. (2007). The gap between educational research and practice: A literature review, symposium and questionnaire. Educational Research and Evaluation, 13, 203-220.

Calderhead, J. (1984). Teachers' classroom decision making. London: Holt.

Carvalho, L. (2010). A sociology of informal learning in/about design. PhD Thesis, The University of Sydney.

Carvalho, L., \& Garduño Freeman, C. (2018). CmyView: Learning by walking and sharing social values. In N. Bonderup Dohn, S. Cranmer, J. Sime, M. de Laat, \& T. Ryberg (Eds.), Networked learning: Reflections and challenges (pp. 167-186). Springer.

Carvalho, L., \& Goodyear, P. (Eds.). (2014). The architecture of productive learning networks. New York: Routledge.

Carvalho, L., \& Goodyear, P. (2018). Design, learning and service innovation. Design Studies, 55, $27-53$. https://doi.org/10.1016/j.destud.2017.09.003.

Carvalho, L., Goodyear, P., \& de Laat, M. (Eds.). (2017). Place-based spaces for networked learning. New York: Routledge.

Chatteur, F. (2011). Design for pedagogy patterns for e-learning. PhD Thesis, The University of Sydney.

Dave, K. (2017). University teachers designing for active learning: Intentions, interpretations and the semantic turn in design. PhD Thesis, The University of Sydney.

Dohn, N. B. (2020). Units of analysis in learning research: Transparency, fit for purpose and purposeful fit. Learning, Culture and Social Interaction, 100426. https://doi.org/10.1016/j.lcsi.2020.100426.

Elen, J. (2020). "Instructional disobedience": A largely neglected phenomenon deserving more systematic research attention. Educational Technology Research and Development, 68, 2021-2032.

Ellis, R., \& Goodyear, P. (2010). Students' experiences of e-learning in higher education: The ecology of sustainable innovation. New York: Routledge. 
Ellis, R., \& Goodyear, P. (2016). Models of learning space: Integrating research on space, place and learning in higher education. Review of Education, 4(2), 149-191. https://doi.org/10.1002/rev3.3056.

Ellis, R., \& Goodyear, P. (2019). The education ecology of universities: Integrating learning, strategy and the academy. New York: Routledge.

Engle, R. A., Lam, D. P., Meyer, X. S., \& Nix, S. E. (2012). How does expansive framing promote transfer? Several proposed explanations and a research agenda for investigating them. Educational Psychologist, 47(3), 215-231. https://doi.org/10.1080/00461520.2012.695678.

Goodyear, P. (1999). Pedagogical frameworks and action research in open and distance learning. European Journal of Open, Distance and E-Learning, 1-7.

Goodyear, P. (2000). Environments for lifelong learning: Ergonomics, architecture and educational design. In J. M. Spector \& T. Anderson (Eds.), Integrated and holistic perspectives on learning, instruction \& technology: Understanding complexity (pp. 1-18). Dordrecht: Kluwer Academic Publishers.

Goodyear, P. (2011). Emerging methodological challenges for educational research. In L. Markauskaite, P. Freebody, \& J. Irwin (Eds.), Methodological choice and design: Scholarship, policy and practice in social and educational research (pp. 253-266). Dordrecht: Springer.

Goodyear, P. (2015). Teaching as design. HERDSA Review of Higher Education, 2, 27-50 Retrieved from http://www.herdsa.org.au/system/files/HERDSARHE2015v02p27.pdf.

Goodyear, P., \& Dimitriadis, Y. (2013). In medias res: Reframing design for learning. Research in Learning Technology, 21. https://doi.org/10.3402/rlt.v21i0.19909.

Goodyear, P., \& Ellis, R. (2008). University students' approaches to learning: Rethinking the place of technology. Distance Education, 29(2), 141-152.

Goodyear, P., \& Retalis, S. (Eds.). (2010). Technology-enhanced learning: Design patterns and pattern languages. Rotterdam: Sense Publishers.

Goodyear, P., Carvalho, L., \& Dohn, N. (2016). Artefacts and activities in the analysis of learning networks. In T. Ryberg, C. Sinclair, S. Bayne, \& M. de Laat (Eds.), Research, boundaries and policy in networked learning (pp. 93-110). New York: Springer.

Goodyear, P., Ellis, R., \& Marmot, A. (2018). Learning spaces research: Framing actionable knowledge. In R. Ellis \& P. Goodyear (Eds.), Spaces of teaching and learning: Integrating perspectives on research and practice (pp. 221-238). Singapore: Springer Nature.

Gunn, W., Otto, T., \& Smith, R. C. (Eds.). (2013). Design anthropology: Theory and practice. London: Bloomsbury.

Hativa, N., \& Goodyear, P. (Eds.). (2002). Teacher thinking, beliefs and knowledge in higher education. Dordrecht: Kluwer Academic Publishers.

Hodges, C., Moore, S., Lockee, B., Trust, T., \& Bond, A. (2020). The difference between emergency remote teaching and online learning. EDUCAUSE Review. Retrieved from https://er.educause.edu/artic les/2020/3/the-difference-between-emergency-remote-teaching-and- online-learning.

Hoogveld, A., Paas, F., Jochems, W., \& van Merrienboer, J. (2002). Exploring teachers' instructional design practices from a systems design perspective. Instructional Science, 30, 291-305.

Ison, R., \& Blackmore, C. (2014). Designing and developing a reflexive learning system for managing systemic change. Systems, 2(2), 119-136.

Kali, Y., Goodyear, P., \& Markauskaite, L. (2011). Researching design practices and design cognition: Contexts, concretisation and pedagogical knowledge-in-pieces. Learning, Media \& Technology, 36(2), 129-149.

Kali, Y., McKenney, S., \& Sagy, O. (2015). Teachers as designers of technology enhanced learning. Instructional Science, 173-180. https://doi.org/10.1007/s11251-014-9343-4.

Koh, J. H. L., \& Kan, R. Y. P. (2020). Students' use of learning management systems and desired e-learning experiences: Are they ready for next generation digital learning environments? Higher Education Research \& Development. https://doi.org/10.1080/07294360.2020.1799949.

Krippendorff, K. (2006). The semantic turn: A new foundation for design. Boca Raton: CRC Press.

Laurillard, D. (2012). Teaching as a design science: Building pedagogical patterns for learning and technology. Abingdon: Routledge.

Lave, J., \& Wenger, E. (1991). Situated learning: Legitimate peripheral participation. Cambridge: Cambridge University Press.

Law, N., Li, L., Herrera, L. F., Chan, A., \& Pong, T. (2017). A pattern language based learning design studio for an analytics informed inter-professional design community. Interaction Design and Architecture $(s)$ Journal, 33, 92-112.

Markauskaite, L., \& Goodyear, P. (2017). Epistemic fluency and professional education: Innovation, knowledgeable action and actionable knowledge. Dordrecht: Springer.

McDonnell, J. (2009). Collaborative negotiation in design: A study of design conversations between architect and building users. CoDesign, 5, 35-50. 
McKenney, S., \& Reeves, T. (2019). Conducting educational design research (2nd ed.). Abingdon: Routledge.

Nelson, H., \& Stolterman, E. (2014). The design way: Intentional change in an unpredictable world (2nd ed.). Cambridge, MA: MIT Press.

Parchoma, G., Koole, M., Morrison, D., Nelson, D., \& Dreaver-Charles, K. (2019). Designing for learning in the yellow house: A comparison of instructional and learning design origins and practices. Higher Education Research \& Development. https://doi.org/10.1080/07294360.2019.1704693.

Pawson, R., \& Tilley, N. (1997). Realistic evaluation. London: Sage.

Pink, S. (2012). Situating everyday life: Practices and places. London: Sage.

Reeves, T. C., \& Lin, L. (2020). The research we have is not the research we need. Educational Technology Research and Development, 68, 1991-2001. https://doi.org/10.1007/s11423-020-09811-3.

Reimann, P. (2011). Design-based research. In L. Markauskaite, P. Freebody, \& J. Irwin (Eds.), Methodological choice and design: Scholarship, policy and practice in social and educational research (pp. 37-50). Dordrecht: Springer.

Reiser, R., \& Dempsey, J. (Eds.). (2017). Trends and issues in instructional design and technology (4th ed.). Upper Saddle River, NJ: Pearson.

Rogoff, B. (2014). Learning by observing and pitching in to family and community endeavors: An orientation. Human Development, 57(2-3), 69-81.

Sandoval, W. (2014). Conjecture mapping: An approach to systematic educational design research. Journal of the Learning Sciences, 23(1), 18-36.

Simonsen, J., Svabo, C., Strandvad, S., Samson, K., Hertzum, M., \& Hansen, O. (2014). Situated design methods. Cambridge, MA: MIT Press.

Spence, N. (2020). Designing for epistemic agency: How university student groups create knowledge and what helps them do it. PhD Thesis, The University of Sydney.

Sun, S. Y. H. (2018). Student configuration and place-making in fully online language learning. Computer Assisted Language Learning, 31(8), 932-959. https://doi.org/10.1080/09588221.2018.14668 08.

Sun, S. Y. H., \& Goodyear, P. (2019). Social co-configuration in online language learning. Australasian Journal of Educational Technology, 36(2), 13-26. https://doi.org/10.14742/ajet.5102.

Vanderlinde, R., \& van Braak, J. (2010). The gap between educational research and practice: Views of teachers, school leaders, intermediaries and researchers. British Educational Research Journal, $36(2), 299-316$.

Wiggins, G., \& McTighe, J. (2005). Understanding by design (2nd ed.). Alexandria: ASCD.

Wong, G., Greenhalgh, T., Westhorp, G., \& Pawson, R. (2012). Realist methods in medical education research: What are they and what can they contribute? Medical Education, 46(1), 89-96. https:// doi.org/10.1111/j.1365-2923.2011.04045.x.

Yeoman, P. (2015). Habits \& habitats: An ethnography of learning entanglement. PhD Thesis, The University of Sydney.

Yeoman, P., \& Carvalho, L. (2019). Moving between material and conceptual structure: Developing a card-based method to support design for learning. Design Studies, 64, 64-89. https://doi. org/10.1016/j.destud.2019.05.003.

Yeoman, P., \& Wilson, S. (2019). Designing for situated learning: Understanding the relations between material properties, designed form and emergent learning activity. British Journal of Educational Technology, 50(5), 2090-2108.

Yeoman, P., \& Carvalho, L., Castañeda, L., \& Adell, J. (2020). Cross-cultural adaptation and user-experience validation of the ACAD Toolkit. Proceedings of the 12th International Conference on Networked Learning. http://www.networkedlearning.aau.dk/digitalAssets/825/825844_09.-yeoman-etal.---cross-cultural-adaptation-and-user-experience-validation-of-the-acad-toolkit.pdf.

Zheng, L. (2015). A systematic literature review of design-based research from 2004 to 2013. Journal of Computers in Education, 2(4), 399-420.

Publisher's Note Springer Nature remains neutral with regard to jurisdictional claims in published maps and institutional affiliations.

Peter Goodyear is an Australian Laureate Fellow and Professor of Education at The University of Sydney in Australia. He has been active in research and innovation in educational technology since the early 1980s, with particular interests in design for learning, networked learning and professional education. 
Lucila Carvalho is a senior lecturer in e-learning and digital technologies at Massey University, New Zealand. Lucila's research explores how culture and social structures shape the design and use of technology, and how technology influences cultural, social and educational experiences. Lucila's research interests are in the areas of design, technology and learning, in formal, non-formal and informal settings.

Pippa Yeoman is a senior lecturer in the Educational Innovation team at The University of Sydney in Australia. She is responsible for the translation of university strategy with respect to learning spaces, and contributes to academic development. Her research focuses on the design and use of convivial environments for learning. 